\title{
Hydrogenation by gold catalysts: an unexpected discovery and a current assessment
}

\author{
Geoffrey C. Bond ${ }^{1}$
}

Received: 14 April 2016/Accepted: 31 July 2016/Published online: 19 September 2016

(C) The Author(s) 2016. This article is published with open access at SpringerLink.com

\begin{abstract}
Gold in the massive state shows little tendency either to chemisorb simple molecules or to act catalytically. The discovery made in 1973 that low loadings of $\mathrm{Au}$ on $\mathrm{Al}_{2} \mathrm{O}_{3}$ and particularly on $\mathrm{SiO}_{2}$ were active in alkene hydrogenation when prepared by thermal decomposition of adsorbed $\mathrm{AuCl}_{4}{ }^{-}$paved the way for later extensive studies of catalysis by this metal. The activity was attributed to that being $\mathrm{Au}$ particles $<4 \mathrm{~nm}$ in size, and it soon appeared that similar catalysts performed the selective hydrogenation of 2-butyne and 1,3-butadiene. Later work strongly suggests that Au particles below $\sim 2.5 \mathrm{~nm}$ in size, and having non-metallic character, are especially adept at $\mathrm{H}_{2}$ chemisorption and $\mathrm{H}_{2}-\mathrm{D}_{2}$ equilibration, and that alkene hydrogenation then occurs in an H-rich environment. Larger Au particles have more limited activity, perhaps associated with atoms of low coordination number and an H-poor environment.
\end{abstract}

Keywords Nanoparticles $\cdot \mathrm{Au} \cdot$ Non-metallic character $\cdot \mathrm{H}_{2}$ chemisorption $\cdot$ Hydrogenation

\section{Introduction}

In the early 1970s, it was generally felt that gold held out little prospect of ever being important in heterogeneous catalysis. In the massive state, it was incorruptible and showed little tendency to adsorb simple molecules at or above ambient temperature; its oxide was thermally unstable. One or two

Geoffrey C. Bond

geoffrey10bond@aol.com

19 Townfield, Rickmansworth WD3 7DD, UK very early attempts to explore its catalytic properties employed quite high temperatures, and the reaction of conversing para- $\mathrm{H}_{2}$ to ortho- $\mathrm{H}_{2}$, which signifies the ability of the catalyst to adsorb $\mathrm{H}_{2}$ dissociatively, required temperatures of 500 to $800 \mathrm{~K}$ with foil and wire [1]. Gold had received mention in numerous patents for catalytic reactions [2], but their worth was uncertain, and the work of Cha and Parravano on the exchange of carbon isotopes between $\mathrm{CO}$ and $\mathrm{CO}_{2}$ using $\mathrm{Au} / \mathrm{MgO}$ catalysts [3] had little relevance to useful catalysis. We believe however it was the observation [4] by Yates that $\mathrm{H}_{2}$ spillover from metal to support occurred on $\mathrm{Au} / \mathrm{SiO}_{2}$ that alerted us to its potential, and because of our interest in this process, P.A. Sermon and I were led to examine the interaction of $\mathrm{HAuCl}_{4}$ with $\mathrm{Al}_{2} \mathrm{O}_{3}$ and $\mathrm{SiO}_{2}$ surfaces [5-7]. Our success in forming materials with significant catalytic activity for hydrogenation, and our demonstration that this was due to the presence of extremely small gold particles strongly suggests that previous failures to observe chemisorption or useful catalysis were caused by the use of the metal either in the massive state or as too large particles.

The work to be recalled was first published in 1973 [5, 6], and although the rates of hydrogenation found were quite modest, it provided the first real evidence for the power of gold in the nanoparticulate state, thus antedating the work of Haruta and his associates on the more useful $\mathrm{CO}$ oxidation [8] by some 15 years. This article is not intended as a general review of gold as an hydrogenation catalyst, as other excellent reviews are available [9-13]: rather it seeks to point out aspects of our early work that have not been fully exploited in the interim, and to explore how recent work on the chemisorption and reactions of $\mathrm{H}_{2}$, and its reaction with unsaturated hydrocarbons, clarifies the behaviour of gold particles less than $10 \mathrm{~nm}$ in size.

A summary of this work was presented at the GOLD2015 Conference in July 2015. 


\section{Catalyst preparation and characterisation}

Well-dispersed $\mathrm{Au}$ catalysts on $\mathrm{SiO}_{2}$ and $\gamma-\mathrm{Al}_{2} \mathrm{O}_{3}$ supports were prepared simply by impregnating them with aqueous solutions of $\mathrm{HAuCl}_{4}$ to give $\mathrm{Au}$ concentrations of $0.01-5 \%$, drying them in vacuo at room temperature for $16 \mathrm{~h}$ and heating them for $48 \mathrm{~h}$ at $393 \mathrm{~K}$ either in air or in vacuo [5-7]. At low concentrations of $\mathrm{Au}\left(\leq 0.25 \%\right.$ for $\mathrm{SiO}_{2} ; \leq 1.25 \%$ for $\gamma$ $\mathrm{Al}_{2} \mathrm{O}_{3}$ ), the precursors, originally yellow, became mauve (Fig. 1), suggesting the formation of Au particles of colloidal dimensions. Those having higher $\mathrm{Au}$ contents were not changed in colour by this treatment, but on $\mathrm{H}_{2}$ reduction at 393-523 K, they became brown (Fig. 1), indicating formation of larger Au particles. Authors that fail to note the colour of their materials miss the cheapest and quickest source of information on their composition and structure.

The interactions of $\mathrm{AuCl}_{4}^{-}$with $\mathrm{SiO}_{2}$ and $\gamma-\mathrm{Al}_{2} \mathrm{O}_{3}$ differ. With $\mathrm{SiO}_{2}$, there is no interaction on drying, as it can be removed by aqueous extraction; however, with 2 and $5 \%$, $\mathrm{Au}$ it is transformed after heating for $60 \mathrm{~h}$ into a state that is not water-extractable. With 2 and $5 \%$, Au on $\gamma-\mathrm{Al}_{2} \mathrm{O}_{3}$, about $1.7-2 \% \mathrm{Au}$, is at once strongly adsorbed and cannot be extracted, but the rest is changed by heating to a non-extractable form. Treatment of the $\gamma-\mathrm{Al}_{2} \mathrm{O}_{3}$ support with $\mathrm{HCl}$ lowers the amount of non-extractable $\mathrm{Au}$ to about $0.5 \%$, showing that the initial attachment is through ion exchange of surface $\mathrm{OH}$ groups. It therefore appears that low concentrations of $\mathrm{AuCl}_{4}{ }^{-}$ on both supports readily decompose to nanoparticulate metallic $\mathrm{Au}$, and indeed, this method has subsequently been applied to many other supports. A disadvantage however is that, particularly with $\gamma-\mathrm{Al}_{2} \mathrm{O}_{3}, \mathrm{Cl}^{-}$may be retained and act as a catalyst poison. This has been removed by aqueous $\mathrm{NaOH}$ [5], but this also dissolved more than $75 \%$ of the Au species. With $\mathrm{SiO}_{2}$, it would be logical to expect that the mean particle size would decrease with Au content, but that there might be a quite wide range of sizes because of the variety of pore dimensions in the support. This aspect of the work was assisted by Mlle. V. Amir-Ibrahimi, visiting from the Strasbourg laboratory of Prof. F. Gault.

Limited transmission electron microscopy and X-ray diffraction measurements of $5 \% \mathrm{Au} / \mathrm{SiO}_{2}\left(\mathrm{H}_{2}\right.$-reduced $)$ and $1.25 \% \mathrm{Au} / \gamma-\mathrm{Al}_{2} \mathrm{O}_{3}$ (air-decomposed) showed [4] mean particle sizes of $20-25 \mathrm{~nm}$; these methods could not be used at $\mathrm{Au}$ loadings of $\leq 0.25 \%$, so the size of the mauve-coloured $\mathrm{Au}$ particles was not determined. However, catalysts having 0.01 and $0.05 \% \mathrm{Au} / \mathrm{SiO}_{2}$ after heating gave esr signals $(100 \mathrm{~K}$, $g=2.07-2.21$ ):

$0.01 \% \mathrm{Au} / \mathrm{SiO}_{2} \ldots$ signal breadth $100 \mathrm{G}$

$0.05 \% \mathrm{Au} / \mathrm{SiO}_{2} \ldots$ ، “ $\quad$ “ $50 \mathrm{G}: 0.002$ spins per $\mathrm{Au}$ atom

Catalysts having 0.25 or $5 \% \mathrm{Au} / \mathrm{SiO}_{2}$ gave no signals. It was concluded at the time that spin-orbit coupling in small $(<4 \mathrm{~nm})$ Au particles having localised atomic orbitals permits esr signals, which are not seen with larger particles having the delocalised molecular orbitals of the massive state. This work as conducted in the Orleans CNRS laboratory of Prof. J.J. Fripiat.

\section{Chemisorption of $\mathrm{H}_{2}$ and $\mathrm{H}_{2}-\mathrm{D}_{2}$ equilibration on supported Au catalysts}

Evidence for the occurrence of $\mathrm{H}_{2}$ chemisorption on supported Au particles came from the work of Yates [4] who detected spillover using $\mathrm{D}_{2}$ and $\mathrm{Au} / \mathrm{SiO}_{2}$ :

$\mathrm{Au}-\mathrm{D}+\mathrm{SiOH} \rightarrow \mathrm{Au}-\mathrm{H}+\mathrm{SiOD}$.

We also found with reduced $5 \% \mathrm{Au} / \mathrm{SiO}_{2}$ that adsorbed $\mathrm{H}$ atoms reacted with $\mathrm{D}_{2}$ at $453 \mathrm{~K}$ :

$\mathrm{Au}-\mathrm{H}+\mathrm{D}_{2} \rightarrow \mathrm{Au}-\mathrm{D}+\mathrm{HD}$.

This occurred quickly and was followed by slower spillover as above, so measuring the HD content can give a rough count of the number of $\mathrm{H}$ atoms adsorbed.

$\mathrm{H}_{2}$ chemisorption has been studied in detail [14-16], as has the $\mathrm{H}_{2}-\mathrm{D}_{2}$ equilibration [17], which also requires dissociative chemisorption of the reactants. With $\mathrm{Au} / \mathrm{Al}_{2} \mathrm{O}_{3}$ prepared by impregnation (IMP) or deposition-precipitation (DP), van Bokhoven et al. [14] observed both weak and strong adsorbed $\mathrm{H}$, depending on the amount retained after pumping at various temperatures (298-473 K), but the location of the two forms was not discussed. $H_{\text {total }}$ rose irregularly in the 3-1-nm range, and $H_{\text {strong }}$ was $<25 \%$ of the total (Fig. 2). It was suggested that chemisorption is limited to edge and corner sites, is weaker than on $\mathrm{Pt}$, and is polarised as $\mathrm{Au}+\rightarrow \mathrm{H}$ according to the
Fig. 1 From left to right: $0.05 \%$ $\mathrm{Au} / \mathrm{SiO}_{2}$ heated in air, $1.25 \% \mathrm{Au} /$ $\mathrm{SiO}_{2}$ heated in air, and $5 \% \mathrm{Au} /$ $\mathrm{SiO}_{2}$ reduced in $\mathrm{H}_{2}$

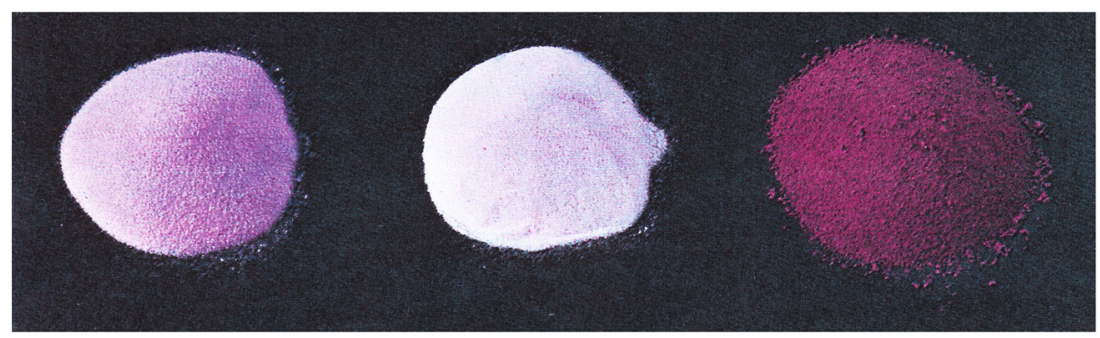




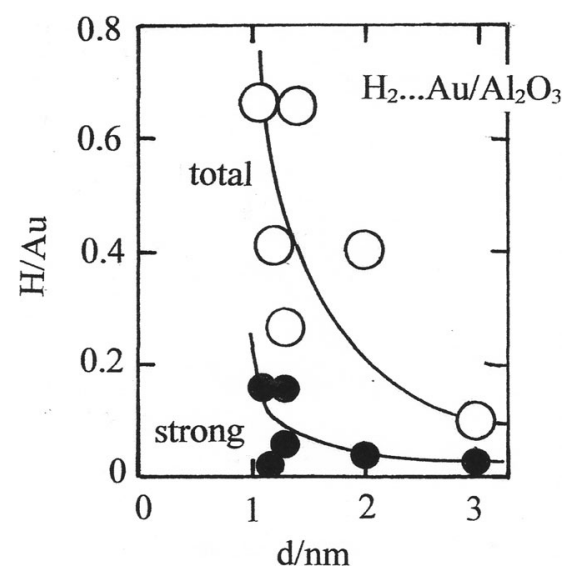

Fig. 2 Chemisorption of $\mathrm{H}_{2}$ on $\mathrm{Au} / \mathrm{Al}_{2} \mathrm{O}_{3}$ as a function of particle size [14]: filled points, strong adsorption; open points, total adsorption

appearance of an XAFS white line. FTIR has been employed [16] to detect a band due to $\mathrm{H}$ atoms adsorbed on Au particles supported on $\mathrm{TiO}_{2}, \mathrm{ZrO}_{2}$ and $\mathrm{CeO}_{2}$ made by DP, and also $\mathrm{H}$ spillover in the case of $\mathrm{Au} / \mathrm{TiO}_{2}$.

$\mathrm{H}_{2}-\mathrm{D}_{2}$ equilibration was followed at $298-373 \mathrm{~K}$ using Au/ $\mathrm{Al}_{2} \mathrm{O}_{3}$; the size effect $(1.1-1.4$ vs. $3 \mathrm{~nm})$ was small $(\sim \times 1.5)$ [14]. With $\mathrm{Au} / \mathrm{TiO}_{2}$ made by DP, a correlation was found between rate of $\mathrm{H}_{2}+\mathrm{D}_{2}$ and low coordination number $(\mathrm{CN})$ $\mathrm{Au}^{0}$ (not $\mathrm{Au}^{\delta+}$ at the periphery of the particles) as identified by IR spectra of adsorbed CO [15]. When prepared by vapour deposition, $\mathrm{Au} / \mathrm{TiO}_{2}$ gave rates that increased smoothly with decreasing size [17] (Fig. 3); these results will be discussed further below.

\section{Hydrogenation of mono-alkenes}

We tested the activity of our Au catalysts for the hydrogenation of 1-pentene using a large excess of $\mathrm{H}_{2}\left(\mathrm{P}_{\mathrm{H}}: \mathrm{P}_{\mathrm{C}} \approx 630\right)$ to

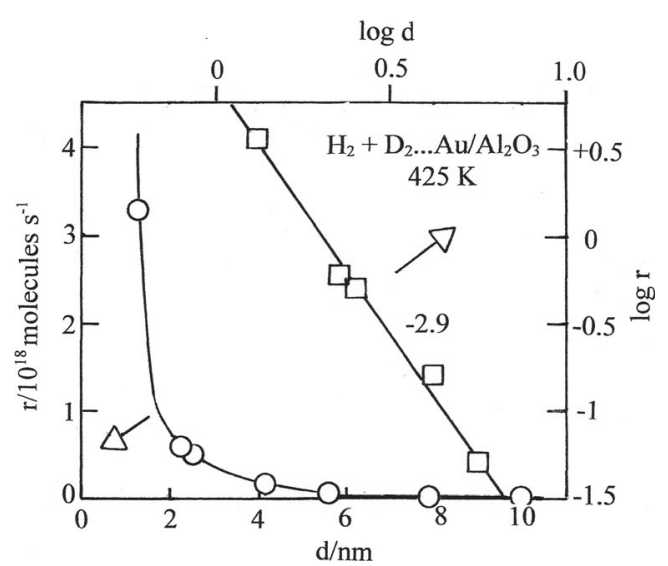

Fig. 3 Rates of $\mathrm{H}_{2}+\mathrm{D}_{2}$ equilibration on $\mathrm{Au} / \mathrm{Al}_{2} \mathrm{O}_{3}$ at $425 \mathrm{~K}$ as a function of particles size [17]: square points, log-log plot facilitate its chemisorption, thinking this to be difficult; at $373 \mathrm{~K}$, conversions were 5-20\% [5-7]. With $\mathrm{Au} / \mathrm{SiO}_{2}$, rates stabilised after initial deactivation: the brown $5 \% \mathrm{Au} / \mathrm{SiO}_{2}$ was quite active, but on decreasing the Au concentration, rates after $1 \mathrm{~h}$ fell to a low value at $1.25 \%$, but then started to rise again at $0.5 \%$ and below, so TOF expressed per g Au increased continuously (Fig. 4). This was ascribed to a rising fraction of very small Au particles. Two or more preparations were made at each Au loading, but rates were not closely reproducible, due perhaps to subtle variations in procedure. Most significantly, 2-pentene isomers formed by doublebond migration (Scheme 1) were only detected with the $5 \%$ $A u$ catalyst. Five-percent $\mathrm{Au} / \gamma-\mathrm{Al}_{2} \mathrm{O}_{3}$ showed stable activity under these conditions, with double-bond migration, but lower Au loadings gave only minimal rates, although appearing by their colour to contain small Au particles. This may have been due to retention of toxic $\mathrm{Cl}^{-}$. Work on this reaction was carried out by P.A. Sermon.

$\mathrm{Au} / \mathrm{SiO}_{2}(0.05$ and $5 \%)$ were active at $453 \mathrm{~K}$ for hydrogenation of ethene, rates roughly following those for exchange of adsorbed $\mathrm{H}$ atoms with $\mathrm{D}_{2}$, which were respectively $13.7 \times 10^{-3}$ and $0.33 \times 10^{-3} \mu \mathrm{mol} \mathrm{g} \mathrm{g}_{\text {cat }}{ }^{-1} \mathrm{~s}^{-1}$; the brown reduced $5 \% \mathrm{Au} / \mathrm{SiO}_{2}$ evidently having many fewer particles able to chemisorb $\mathrm{H}_{2}(d \sim 25 \mathrm{~nm})$. With the collaboration of P.B. Wells at the University of Hull, we moved on to try the reaction of ethene with $\mathrm{D}_{2}$, since the products of this reaction should help to characterise the active centre [7]. Poor mass balances were initially found at $453 \mathrm{~K}$, caused by the occurrence of D spillover as found by Yates [4]:

$\mathrm{Si}-\mathrm{OH}+\mathrm{D}^{*} \rightarrow \mathrm{Si}-\mathrm{OD}+\mathrm{H}^{*}$,

where * represents the adsorbed state or (below) a single adsorption site. After the exchange had come to equilibrium, mass balances were satisfactory. Product analysis of reaction at $448 \mathrm{~K}$ using $\mathrm{P}_{\mathrm{D}}=\mathrm{P}_{\mathrm{E}}$ showed ethene exchange as well as

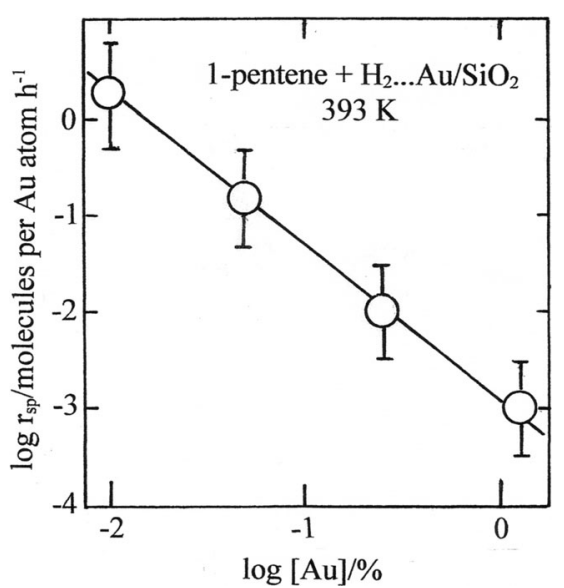

Fig. 4 Log-log plot of specific rates for 1-pentene hydrogenation on $\mathrm{Au} /$ $\mathrm{SiO}_{2}$ at $393 \mathrm{~K}$ vs. Au loading [7] 


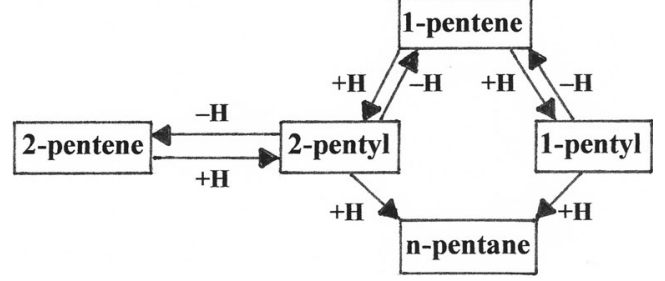

Scheme 1 Steps in the hydrogenation of 2-pentene

deuterated ethanes (Fig. 5). This is explained in the HoriutiPolanyi mechanism by ethyl reversal, e.g.

$\mathrm{C}_{2} \mathrm{H}_{4} *+\mathrm{D} * \rightarrow \mathrm{C}_{2} \mathrm{H}_{4} \mathrm{D} *+* \rightarrow \mathrm{C}_{2} \mathrm{H}_{3} \mathrm{D} *+\mathrm{H}^{*}$.

In general, putting $X=\mathrm{H}$ or D

$\mathrm{C}_{2} \mathrm{X}_{4} \stackrel{\leftrightarrow}{\leftrightarrow} \mathrm{C}_{2} \mathrm{X}_{4} * \stackrel{+\mathrm{x}}{\longleftrightarrow} \mathrm{C}_{2} \mathrm{X}_{5} * \stackrel{+\mathrm{x}}{\rightarrow} \mathrm{C}_{2} \mathrm{X}_{6}$

The relative importance of each step is assigned a parameter:

$\mathrm{C}_{2} \mathrm{X}_{4} \stackrel{1}{\leftarrow} \mathrm{C}_{2} \mathrm{X}_{4} * \stackrel{\mathrm{p}}{\rightarrow} \mathrm{C}_{2} \mathrm{X}_{5} *$

$\mathrm{C}_{2} \mathrm{X}_{4} * \stackrel{\mathrm{r}}{\leftarrow} \mathrm{C}_{2} \mathrm{X}_{5} * \stackrel{1}{\rightarrow} \mathrm{C}_{2} \mathrm{X}_{6}$

The chance of $X=\mathrm{D}$ is $q$ in the first step and $s$ in the second. Product yields calculated for $p=9, r=29, q=0.5$ and $s=2$ are shown in the figure: they are quite like those given by Pt/ $\mathrm{Al}_{2} \mathrm{O}_{3}$ catalysts [18], which show efficient ethyl formation and reversal, but inefficient ethene desorption and ethane formation.

\section{Hydrogenation of alkynes}

Work carried out at the Glasgow University by G. Webb and D.A. Buchanan [5] showed that $1 \% \mathrm{Au} / \mathrm{AlO}(\mathrm{OH})$ catalysed

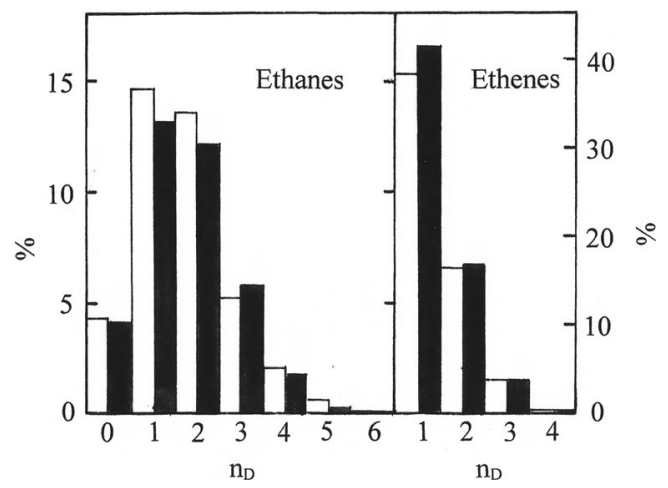

Fig. 5 Deuterated ethenes and ethanes formed from $\mathrm{C}_{2} \mathrm{H}_{4}+\mathrm{D}_{2}$ over $5 \%$ $\mathrm{Au} / \mathrm{SiO}_{2}$ at $453 \mathrm{~K}$ : filled bars, experimental values; open bars, values calculated from the parameters given in the text [7] hydrogenation of 2-butyne at 400-490 K giving only Z-2butene $(80 \%)$ and E-2-butene $(20 \%)$. Formation of the latter may occur either via isomerisation to 1,2-butadiene or via a planar free-radical half-hydrogenated state [19].

Completely selective hydrogenation of ethyne and other alkynes on $\mathrm{Au}$ catalysts has frequently been observed, rates being faster than for those of alkenes [20-22], unlike the situation with metals of groups 8 to 10 [19]; detailed kinetic and mechanistic studies are however quite rare [22]. In particular, it is not clear whether high selectivity arises from surfaces partly covered with 'carbonaceous residues', as is thought to be the case with Pd catalysts [23], but probably not, as high selectivity is shown from the start [22].

\section{Hydrogenation of 1,3-butadiene}

One-percent $\mathrm{Au} / \mathrm{AlO}(\mathrm{OH})$ and $1 \% \mathrm{Au} / \gamma-\mathrm{Al}_{2} \mathrm{O}_{3}$ also effected hydrogenation of 1,3-butadiene at 400-490 K, giving only the butene isomers (see Table 1) and no n-butane; attempts to study the reaction with $\mathrm{D}_{2}$ were frustrated by spillover problems [24].

There have been a number of subsequent studies of this reaction. Although three reports showed surprisingly little or no effect of size on rate $[17,20,29]$, there are marked variations of product yields (Table 1), which may arise from factors other than size, such as temperature, state of deactivation (which is mentioned in all studies), the $\mathrm{H}_{2}$ /butadiene ratio, reduction temperature, method of preparation and mode of operation. 1-Butene is always the major product (50-75\%), but the $\mathrm{E} / \mathrm{Z}$ (trans/cis) ratio is variable, being usually $\sim 0.3-0.7$ for $2-9 \mathrm{~nm}$ particles [20, 29], rising slowly with size [29]. Values between 1.2 and 2.2 probably arise from larger particles [24-26, 28], but where a broad distribution is reported [24], it is impossible to know what size of particles was actually operative.

Complete selectivity to the butenes is universally reported, and added propene is unreactive while any butadiene remains [20]. After that, it reacts slowly, while the butene isomers equilibrate but are not hydrogenated. The same effect has been seen [24] in a static system after the butadiene concentration has fallen by 60 or $90 \%$ (depending on the catalyst), but no hydrogenation occurs. Similarly, 1 -butene and $\mathrm{H}_{2}$ react at $473 \mathrm{~K}$ to give only 2-butene isomers. For the analogous reactions of 1-pentene, see Scheme 1.

The one universally agreed observation is that both with alkadienes and alkynes the product alkenes are quickly expelled from the surface, and, requiring the same type of site, are unable to re-adsorb while much of the multi-unsaturated molecule remains. 
Table 1 Product distributions from 1,3-butadiene hydrogenation

\begin{tabular}{|c|c|c|c|c|c|c|c|c|c|c|c|}
\hline$[\mathrm{Au}] / \%$ & Support & $\mathrm{d} / \mathrm{nm}$ & Method & $\mathrm{H}_{2} / \mathrm{bd}$ & $\mathrm{T} / \mathrm{K}$ & $\% 1-b$ & $\% \mathrm{Z}-2-\mathrm{b}$ & $\%$ E-2-b & $\mathrm{E} / \mathrm{Z}$ & Notes & Reference \\
\hline \multirow[t]{2}{*}{1} & \multirow[t]{2}{*}{$\mathrm{AlO}(\mathrm{OH})$} & \multirow[t]{2}{*}{$\sim 5$} & \multirow[t]{2}{*}{ IMP } & \multirow[t]{2}{*}{2} & 473 & 50 & 18 & 32 & 1.78 & \multirow[t]{2}{*}{1} & \multirow[t]{2}{*}[24]{} \\
\hline & & & & & 553 & 52 & 21 & 27 & 1.28 & & \\
\hline \multirow[t]{2}{*}{1} & \multirow[t]{2}{*}{$\mathrm{Al}_{2} \mathrm{O}_{3}$} & \multirow[t]{2}{*}{$\sim 10$} & \multirow[t]{2}{*}{ IMP } & \multirow[t]{2}{*}{2} & 443 & 58 & 13 & 28 & 2.16 & \multirow[t]{2}{*}{1} & \multirow[t]{2}{*}[24]{} \\
\hline & & & & & 553 & 60 & 15 & 25 & 1.67 & & \\
\hline 1 & $\mathrm{Al}_{2} \mathrm{O}_{3}$ & 2 & DP & 66 & 443 & 62.5 & 29 & 8.5 & 0.29 & 2 & {$[20,21]$} \\
\hline$?$ & $\mathrm{Al}_{2} \mathrm{O}_{3}$ & - & VD & 10 & $\sim 523$ & 57 & 19 & 22 & 1.16 & 2 & {$[25,26]$} \\
\hline \multirow[t]{3}{*}{1} & $\mathrm{Al}_{2} \mathrm{O}_{3}$ & $\sim 1$ & DP & 49 & 418 & 75 & 17 & 8 & 0.47 & & \multirow[t]{3}{*}[27]{} \\
\hline & $\mathrm{SiO} 2$ & $\sim 1$ & GG & 49 & 416 & 71 & 20 & 9 & 0.45 & & \\
\hline & $\mathrm{TiO} 2$ & $\sim 1$ & GG & 49 & 415 & 70 & 23 & 7 & 0.30 & & \\
\hline- & - & - & Film & 2 & 431 & 73 & 11 & 16 & 1.45 & & {$[28]$} \\
\hline \multirow[t]{3}{*}{3.7} & $\mathrm{SiO}_{2}$ & \multirow[t]{3}{*}{2.7} & \multirow[t]{3}{*}{ IMP } & \multirow[t]{3}{*}{49} & 393 & 62 & 32 & 6 & \multirow[t]{3}{*}{0.19} & & \multirow[t]{3}{*}{ [29] } \\
\hline & 3.8 & & & & 61 & 30 & 9 & 0.3 & & & \\
\hline & 9.1 & & & & 67 & 20 & 13 & 0.67 & & & \\
\hline
\end{tabular}

In the column headings, $d=$ mean Au particle size; $b d=1$,3-butadiene; 1 - $b=1$-butene; $Z-2-b=\mathrm{Z}$ (cis)-2-butene; $E$-2- $b=\mathrm{E}$ (trans)-2-butene

(1) $\mathrm{H}_{2}$ reduced at $523 \mathrm{~K}$; static mode; yields independent of $\mathrm{H}_{2} /$ bd ratio

(2) $\mathrm{H}_{2}$ reduced at $573 \mathrm{~K}$; flow mode

$I M P$ impregnation, $D P$ deposition-precipitation, $V D$ vapour deposition, $G G$ gas-phase grafting

\section{Kinetics: deactivation and homologation}

Limited information is available on orders of reaction for hydrogenation of unsaturated hydrocarbons (Table 2); they mainly show $\mathrm{H}_{2}$ orders of unity (or 0.7 ) [20] and zero or 0.4 orders for alkenes, zero or 0.2 orders for butadiene and -1 order for ethyne. These suggest that at the active site alkenes and alkadienes are quite strongly adsorbed, but do not inhibit $\mathrm{H}_{2}$ adsorption as is the case with ethyne. Further analysis is made difficult by the fact that different reaction modes are used (continuous isothermal flow [7], non-isothermal flow [24], pulsed flow [30] and static [24]), each of which may lead to various extents of coverage by unreactive species, and which make comparison of specific rates almost impossible. Almost every work with Au catalysts reports deactivation: it is a common feature of all metal-catalysed hydrogenations, and is usually attributed to initial dehydrogenation, followed by polymerisation. Its widespread occurrence with Au may reflect low $\mathrm{H}$ coverages, which militate against hydrogenation.

Table 2 Orders of reaction. $r=\mathrm{kP}_{\mathrm{A}}{ }^{x} \mathrm{P}_{\mathrm{H}}^{y}$

\begin{tabular}{lllllll}
\hline$[\mathrm{Au}] / \%$ & Support & $\mathrm{T} / \mathrm{K}$ & Molecule & $x$ & $y$ & Reference \\
\hline 5 & $\mathrm{SiO}_{2}$ & 453 & $\mathrm{C}_{2} \mathrm{H}_{4}$ & 0.4 & 1 & {$[7]$} \\
1 & $\mathrm{Al}_{2} \mathrm{O}_{3}$ & 443 & $\mathrm{C}_{3} \mathrm{H}_{6}$ & 0 & 1 & {$[20]$} \\
2 & $\mathrm{CeO}_{2}$ & $?$ & $\mathrm{C}_{2} \mathrm{H}_{2}$ & -1 & 1 & {$[22]$} \\
1 & $\mathrm{Al}_{2} \mathrm{O}_{3}$ & 443 & $\mathrm{C}_{4} \mathrm{H}_{6}$ & 0.2 & 0.7 & {$[20]$} \\
1 & $\mathrm{AlO}(\mathrm{OH})$ & 473 & $\mathrm{C}_{4} \mathrm{H}_{6}$ & 0 & 1 & {$[24]$} \\
\hline
\end{tabular}

Note: $C_{4} H_{6}=1,3$-butadiene
In the case of ethene $+\mathrm{H}_{2}$ [7], higher products $\left(\mathrm{C}_{3}-\mathrm{C}_{6}\right)$ were detected, showing that inhibiting species may vacate the surface under some conditions, and that $\mathrm{C}-\mathrm{C}$ fission takes place as well as homologation.

\section{Physical changes at very small particle sizes and their interpretation}

The changes that occur to the physical properties of very small $\mathrm{Au}$ particles have been the focus of attention for physicists, material scientists and theoreticians. They have recently been reviewed [31] and discussed for their relevance to understanding the variation of catalytic activity in the size range below $10 \mathrm{~nm}$. Some of the changes are quite dramatic: for example, the electrical conductivity at $4 \mathrm{~nm}$ is $10^{7}$ times smaller than the bulk value, but probably most significant are the appearance of a band gap above the Fermi energy, associated with our observed esr signal [7], and the decrease in interatomic spacing from 0.288 to $0.245 \mathrm{~nm}$. The $d$-band spin-orbit splitting begins to fall below about $2 \mathrm{~nm}$ from the bulk value of $2.54 \mathrm{eV}$ to the towards the atomic value of $1.5 \mathrm{eV}$ [32]. Particles smaller than about $2.5 \mathrm{~nm}$ appear to have lost their metallic character, and to behave rather as 'giant molecules'. Attempts have been made to represent these changes by band-structure diagrams for small particles that include a band gap above the Fermi energy [31]; in one of our earliest papers, we ascribed them to a 'transmutation' to a state more like Pt, an idea that is not totally in conflict with the band-structure picture or with the products formed in the $\mathrm{C}_{2} \mathrm{H}_{4}+\mathrm{D}_{2}$ reaction [7]. 
While so many physical characteristics exhibit similar trends, one cannot meaningfully try to connect catalytic performance with any single one, and in any event, merely establishing a correlation does not explain its cause. Catalytic activity is the result of the totality of all relevant factors acting in concert, but this has not prevented chemists from trying to assign causes for the marked increase in activity below $10 \mathrm{~nm}$. Briefly, there are two complementary ideas that have been considered: (i) a chemical approach that associates activity with edge and corner atoms by assigning them favourable electronic structures or with peripheral atoms that may additionally be influenced by contact with the support; and (ii) a physical approach that ascribes it to change in the electronic structure of the whole particle (which inevitably is reflected in that of surface atoms), and in particular, that credits the activity jump at $\sim 2.5 \mathrm{~nm}$ to a change from metallic to non-metallic behaviour [17].

The two viewpoints are in fact almost equivalent, because the non-metallic condition arises because of the rise in the fraction of surface atoms lacking a full complement of neighbours (Fig. 6), whose electronic structure, differing from that of other atoms by reason of their smaller interatomic bonding, comes to affect the whole particle. The fraction of corner atoms on the perfect cubo-octahedral model rises abruptly below $2 \mathrm{~nm}[13,14]$ (Fig. 7) from 20 to $75 \%$ at $1 \mathrm{~nm}$, and on the spherical model, the dispersion $\left(n_{s} / n_{t}\right)$ rises from $40 \%$ at $3 \mathrm{~nm}$ to $65 \%$ at $2 \mathrm{~nm}$. For particles having about 200 atoms, the change from a metallic to a non-metallic state therefore occurs when about half of the atoms are superficial and 1/3rd are 'edge-corner': the mean $\mathrm{CN}$ of all atoms has fallen from $\sim 12$ to $\sim 9$ and of the surface atoms from $\sim 9$ to $\sim 5$, and the communal electron bands can no longer be sustained.

In addition to these inherent size effects, there is the possibility of metal-support interactions, the importance of which should increase as particle size becomes smaller. They have been widely studied and discussed in the past, but chiefly in connection with the metals of groups 8 to 10 , and their role in gold catalysis is not often considered, except as modifying the properties of atoms at the particle's periphery.

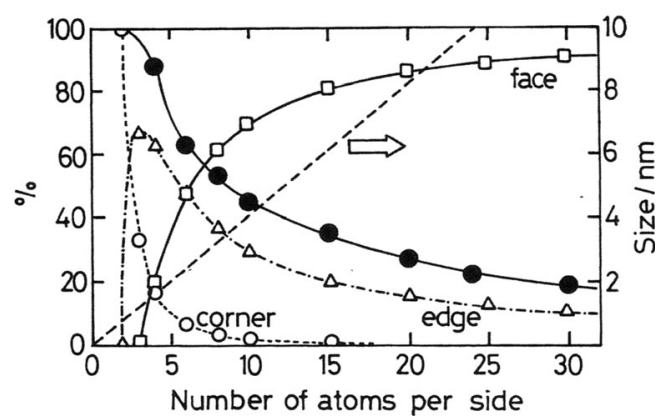

Fig. 6 Fractions of surface atoms for perfect fcc cubo-octrahedra as a function of the number of atoms per side: the filled points give the dispersion and the dashed line the size

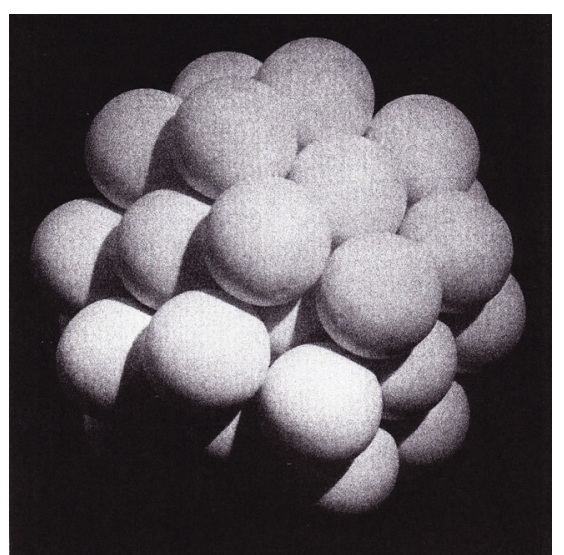

Fig. 7 Model of a small ( 2 nm) face-centred cubic (fcc) particle: 90\% of the atoms are superficial

\section{Variation in catalytic activity at very small particle sizes and its interpretation}

Received wisdom states that $\mathrm{H}_{2}$ molecules must chemisorb by dissociation on catalysts active for hydrogenation. We must therefore examine the experimental evidence bearing on the question of the greater importance of low $\mathrm{CN}$ atoms for facilitating this. We cannot directly relate our results for 1pentene $+\mathrm{H}_{2}$ (Fig. 4) to a decrease in mean size, because decreasing Au content almost certainly results in the formation of fewer particles, so that lowering this by a factor of $10^{2}$ will not lead to a fall in the mean size of the same factor. Some other explanation has therefore to be sought for the very large change in specific rate.

One possible explanation has already been suggested [30] (Fig. 8). The areas under the curves reflect the Au content; as the mean size goes down, most importantly, the fraction having sizes below $2.5 \mathrm{~nm}$ rises dramatically, and that having size below $4 \mathrm{~nm}$ mirrors the appearance of the esr signal. The $\mathrm{H} / \mathrm{Au}_{\text {tot }}$ rises to 0.7 at about $1.2 \mathrm{~nm}$ [14], although Corma [15] has also ruled out peripheral atoms as the locus of $\mathrm{H}_{2}$ chemisorption from evidence on IR spectra of adsorbed $\mathrm{CO}$, favouring other low coordination number atoms. The

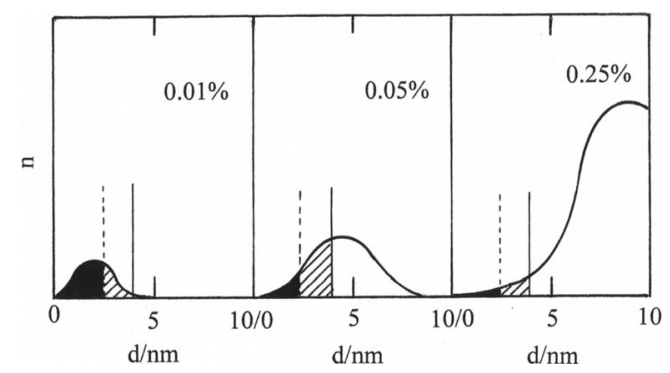

Fig. 8 Schematic diagram showing how for size distributions having maxima at $\sim 2, \sim 4.5$ and $\sim 9 \mathrm{~nm}$ the fractions of particles below 2.5 and $4 \mathrm{~nm}$ may vary with Au loadings from 0.01 to $0.25 \%$ [31] 
conclusion [17] that the rate of the $\mathrm{H}_{2}+\mathrm{D}_{2}$ reaction depends on the number of peripheral atoms is risky because at mean sizes at and above $5.6 \mathrm{~nm}$, the distribution becomes binodal; the log-log plot of rate vs. mean size (Fig. 3) has a slope of -2.9 , and the rate appears to be proportional to the fraction of atoms smaller than $\sim 2.5 \mathrm{~nm}$ and certainly not to the fraction smaller than $\sim 4 \mathrm{~nm}$. The importance of recording size distributions is thereby emphasised [17,29].

We therefore suggest that below about $2.5 \mathrm{~nm}$, there is a step-change increase in rates of reactions involving $\mathrm{H}_{2}$ of at least a factor of 10. This is associated not only with a rapid increase in low coordination number Au atoms able to bond $H$ atoms but also with a change in the reactivity of those atoms due to more favourable strength of the $H-A u$ bond. Similar discontinuous change in the rate of $\mathrm{CO}$ oxidation has already been demonstrated [31] by a much larger factor $(\times 150)$.

Some significant observations concerning factors other than rate made in our original work and since throw further light on this question. Small particles (i.e. $<2.5 \mathrm{~nm}$ ) hydrogenate 1-pentene without giving double-bond migration [7]; the necessary alkyl reversal (Scheme 1) requires a site to accept an $\mathrm{H}$ atom from the 2-pentyl species, and if this is not available by reason of the high $\mathrm{H}$ coverage, its conversion to $n$-pentane will be favoured. Ethene exchange should not be expected under these circumstances, and we should expect to see different orders of reaction; we may therefore designate this region as being 'H-rich'.

Since activity rises again when $5 \% \mathrm{Au} / \mathrm{SiO}_{2}$ is reduced, another reaction environment must apply, in which $\mathrm{H}_{2}$ is less well chemisorbed, perhaps only on corner atoms of larger particles not giving an esr signal, so that double-bond migration can occur alongside hydrogenation. On such particles, the reaction of ethene with $\mathrm{D}_{2}$ affords exchanged ethenes, after the manner of $\mathrm{Pt}$ [18]. The surface of these larger particles is therefore deemed to be 'H-poor'. The difference in the rates of exchange of adsorbed $\mathrm{H}$ atoms with $\mathrm{D}_{2}$ confirms the large alteration in their amount retained with size.

In butadiene hydrogenation, isomerisation of the product butenes starts at conversions of 60 or $80 \%$ (static system, size respectively $\sim 25$ or $15 \mathrm{~nm}$ [24]) and $90 \%$ (flow, size $\sim 2 \mathrm{~nm}[20])$. Good selectivity requires not only initial absence of butane but also its persistent absence while much butadiene remains, so larger particles are less selective than small ones. Surprisingly however, after the butadiene has all gone, propene, present as a competing alkene, reacts with $\mathrm{H}_{2}$ in a flow system ( $T>473 \mathrm{~K}$ [20]) while butenes isomerise without being hydrogenated; and 1-butene alone also isomerises $(\mathrm{Au} / \mathrm{AlO}(\mathrm{OH})$ at $473 \mathrm{~K}$, size $\sim 15 \mathrm{~nm})$ but is not hydrogenated [24]. Thus, on larger H-poor Au particles [24] or on small but contaminated H-rich particles [20] on which the effective $\mathrm{H}$ concentration is low, double-bond migration can occur without concomitant hydrogenation. This condition would seem to suggest the possibility of developing a process for converting terminal to internal alkenes without their hydrogenation.

There appears to be a trend in the $\mathrm{E} / \mathrm{Z}$ ratio of the 2-butenes formed from butadiene, the $\mathrm{Z}$ (cis) arising from the synconformation of the reactant or intermediate being preferred on small particles $[17,24,29]$, while the $\mathrm{E}$ (trans) isomer coming from the anti-conformation is preferred on large particles [24, 28]. Density-functional theory calculations [24] show that on an $\mathrm{Au}_{19}$ cluster (where only one atom is neither edge nor corner), the syn-conformation of butadiene is energetically favoured over the anti through orbital matching. This therefore corresponds to the H-rich scenario; however, the syn form is also stabler on plane surfaces although by a smaller margin.

Perhaps the most surprising observation made repeatedly is that the rate of butadiene hydrogenation is wholly or substantially structure-insensitve to sizes of $\sim 9 \mathrm{~nm}$ $[17,24,29]$, near-perfect initial selectivity occurring throughout. This is in contrast to the reaction of ethyne + $\mathrm{H}_{2}$ which on $\mathrm{Au} / \mathrm{Al}_{2} \mathrm{O}_{3}$ at $523 \mathrm{~K}$ showed marked decrease in rate as size increased from 2 to $8 \mathrm{~nm}$ [22]. Even more astonishing is the lack of discussion of the butadiene case, since, if $\mathrm{H}_{2}$ dissociation is required, larger particles should be almost inactive. One possibility is that the reaction is initiated by a Rideal-Eley step involving $\mathrm{H}_{2}$ dissociation only via reaction with adsorbed butadiene. Other reactions involving $\mathrm{H}$ or $\mathrm{H}_{2}$ (crotonaldehyde $+\mathrm{H}_{2}, \mathrm{H}_{2}+\mathrm{D}_{2}$, $\mathrm{HCOOH}$ decomposition [33]) all show rapid increase in rate as the 'H-rich' state is approached below $\sim 2 \mathrm{~nm}$.

\section{What has not been done — and why}

So let us see which of the things touched on in our early work have not been followed up, and which have, leading to still unsolved problems.

- No further use has been made of Au particles formed by thermal decomposition of $\mathrm{AuCl}_{4}{ }^{-}$for hydrogenations. All further studies have involved either calcination or $\mathrm{H}_{2}$ reduction or both, although reduction does not necessarily lead to particle growth [20].

- Little more has been done using $\mathrm{D}_{2}$ to investigate mechanisms. One study of butadiene $+\mathrm{D}_{2}$ was frustrated by H/D spillover [24]; a detailed study of the reaction of propene with $\mathrm{D}_{2}$ has also been reported, indicating even greater complexity than usual [34].

- Little more seems to have been reported on the esr of small Au particles: one study [35] on $3 \mathrm{~nm}$ particles detected spins ( $g=2.26$, mean width $200 \mathrm{G}$ ) arising from 'severe inhibition of the electron-phonon interaction'. Particles 2$8 \mathrm{~nm}$ in size have also revealed similar spin effects [36]. 
- Comparison of activities/TOFs between work using different reaction modes is difficult; the static mode allows study of slower rates or lower temperatures.

- Frustration is caused by inadequate reporting of essential information: TEM size distributions are to be preferred over a single mean size with a standard deviation value, even for very small particles.

- There has been no systematic work on the comparative merits of different supports, but the activity commonly found with $\mathrm{Au}$ on ceramic supports suggests that metalsupport interactions are unimportant and that atoms at the periphery of particles have no special role.

- Study of the amount of chemisorbed $\mathrm{H}_{2}$ and of the properties of adsorbed $\mathrm{H}$ atoms, and of their reaction with unsaturated hydrocarbons, which embrace a number of sensitive mechanistic features, provides an additional powerful method for the study of very small Au particles and deserves further study.

- It remains a task for theoreticians to explain (in terms that chemists can understand) why small non-metallic Au particles are so much more adept at chemisorption than larger ones.

- A full account of the preparation, properties and uses of gold nanoparticles [37] may satisfy readers needing further information on this subject.

Open Access This article is distributed under the terms of the Creative Commons Attribution 4.0 International License (http:// creativecommons.org/licenses/by/4.0/), which permits unrestricted use, distribution, and reproduction in any medium, provided you give appropriate credit to the original author(s) and the source, provide a link to the Creative Commons license, and indicate if changes were made.

\section{References}

1. Bond GC (1962) Catalysis by Metals. Academic Press, London 519p

2. Bond GC (2008) The early history of catalysis by gold. Gold Bull 41:235-241

3. Cha GY, Parravano G (1970) Surface reactivity of supported gold: 1. Oxygen transfer between $\mathrm{CO}$ and $\mathrm{CO}_{2}$. J Catal 18:200-211

4. Yates DJC (1969) Spectroscopic investigations of gold surfaces. J Colloid Interface Sci 29:194-204

5. Bond GC, Sermon PA, Webb G, Buchanan DA and Wells PB (1973) Hydrogenation over supported gold catalysts. J Chem Soc Chem Comm 444-445

6. Bond GC, Sermon PA (1973) Gold catalysts for olefin hydrogenation. Gold Bull 6:102-105

7. Sermon PA, Bond GC, Wells PB (1979) Hydrogenation of alkenes over supported gold. J Chem Soc Faraday Trans 75:385-394

8. Haruta M, Kobayashi T, Sano H, Yamada N (1987) Novel gold catalysts for the oxidation of carbom monoxide far below $0^{\circ} \mathrm{C}$. Chem Lett 16:405-408

9. Cárdenas-Lizana F, Keane MA (2013) The development of gold catalysts for use in hydrogenation reactions. J. Mater Sci 48:543-564
10. McEwan L, Julius M, Roberts S, Fletcher JCQ (2010) A review of the use of gold catalysts in selective hydrogenation reactions. Gold Bull 43:298-306

11. Nikolaev SA, Zanaveskin LN, Smirnov VV, Averyanov VA, Zanaveskin KL (2009) Catalytic hydrogenation of alkyne and alkadiene impurities. Practical and theoretical aspects. Russ Chem Rev 78:231-247

12. Gluhoi AC, Bakker JW, Nieuwenhuys BE (2010) Gold, still a surprising catalyst: selective hydrogenation of acetylene to ethylene over Au nanoparticles. Catal Today 154:13-20

13. Kartusch C, van Bokhoven JA (2009) Hydrogenation over gold catalysts: the interaction of gold with hydrogen. Gold Bull 42:343-348

14. Bus E, Miller JT, van Bokhoven JA (2005) Hydrogen chemisorption on $\mathrm{Al}_{2} \mathrm{O}_{3}$ - supported gold catalysts. J Phys Chem 109: 14581-14587

15. Boronat M, Concepción P, Corma A (2009) Unravelling the nature of gold surface sites by combining IR spectroscopy and DFT calculations: implications in catalysis. J Phys Chem C 113:16772-16784

16. Manzoli M, Chiorino M, Vindigni F, Boccuzzi F (2012) Hydrogen interaction with gold nanoparticles and clusters supported on different oxides: an FTIR study. Catal Today 181:62-67

17. Fujitani T, Nakamura I, Akita T, Okumura M, Haruta M (2009) Hydrogen dissociation on gold clusters. Angew Chem Int Ed 48:9515-9518

18. Bond GC (2005) Metal-catalysed reactions of hydrocarbons. Springer, New York Ch 7

19. Bond GC (2005) Metal-catalysed reactions of hydrocarbons. Springer, New York Ch 8

20. Hugon A, Delannoy L, Louis C (2008) Supported gold catalysts for selective hydrogenation of 1,3-butadiene in the presence of excess of alkenes. Gold Bull 41:127-138

21. Hugon A, Delannoy L, Louis C (2009) Influence of reactant concentration in selective hydrogenation of 1,3-butadiene over supported gold catalysts under alkene rich conditions. Gold Bull 44:310-320

22. Azizi Y, Petit C, Pitchon V (2008) Formation of polymer-grade ethylene by selective hydrogenation of acetylene over $\mathrm{Au} / \mathrm{CeO}_{2}$ catalyst. J Catal 256:338-344

23. Borodziński A, Bond GC (2006) Selective hydrogenation of ethyne in ethene-rich streams on palladium catalysts, Part 1: Effect of changes to the catalyst during reaction. Catal Rev 48:91-144

24. Buchanan DA, Webb G (1975) Catalysis by Group IB metals: Part 1- Reactions of 1,3- butadiene with hydrogen and with deuterium catalysed by alumina-supported gold. J Chem Soc Faraday Trans 71:134-144

25. Schimpf S, Lucas M, Mohr C, Rodemerck U, Brückner A, Radnik J, Hofmeister, Claus P (2002) Supported gold nanoparticles: indepth catalyst characterization and application in hydrogenation and oxidation reactions. Catal Today 72:63-78

26. Claus P, Brückner A, Mohr C, Hofmeister H (2000) Supported gold nanoparticles from quantum dot to macroscopic size scale;effect of electronic and structural properties on catalytic hydrogenation of conjugated functional groups. J Am Chem Soc 122:11430-11439

27. Okumura M, Akita T, Haruta M (2002) Hydrogenation of 1,3-butadiene and of crotonaldehyde over highly dispersed Au catalysts. Catal Today 74:265-269

28. Moyes RB, Wells PB, Grant J, Salman N (2002) Electronic effects in butadiene hydrogenation catalysed by the transition metals. Appl Catal A Gen 229:251-259

29. Yang X-F, Wang A-Q, Wang Y-L, Zhang T, Li J (2010) Unusual selectivity of gold catalysts for hydrogenation of 1,3-butadiene toward cis-2-butene: a joint experimental and theoretical study. J Phys Chem C 114:3131-3139 
30. Lopez-Sanchez JA, Lennon D (2005) The use of titania- and iron oxide-supported gold catalysts for the hydrogenation of propyne. App Catal A: Gen 291:233-237

31. Bond GC (2011) The effect of the metal to non-metal transition on the activity of gold catalysts. Faraday Discuss 152: 277-291

32. Haruta M (2011) Role of perimeter interfaces in catalysis by gold nanoparticles. Faraday Discuss 152:11-32

33. Bond GC (2012) Chemisorption and reactions of small molecules on small gold particles. Molecules 17:1716-1743

34. Naito S, Tanimoto M (1988) Mechanism of deuterium addition and exchange of propene over silica-supported gold and silver catalysts. J Chem Soc Faraday Trans I 84:41154124

35. Dupree R, Fobwood CT, Asmith MJ (1967) Conduction electron spin resonance in small particles of gold. Phys Status Solidi B 24:525-530

36. Monot R, Châtelaine A, Borel J-P (1971) Small gold particles

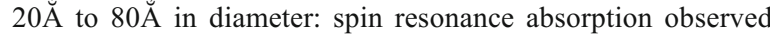
in all samples attributed to conduction electrons. Phys Lett A 34:57-58

37. Louis C, Pluchery O (eds) (2013) Gold Nanoparticles for Physics, Chemistry and Biology. Imperial College Press, London $395 \mathrm{p}$ 